\title{
Homer Isoforms Differentially Regulate Cocaine-Induced Neuroplasticity
}

\author{
Karen K Szumlinski*,', Kenneth E Abernathy', Erik B Oleson', Matthias Klugmann², Kevin D Lominac', \\ Dao-Yao $\mathrm{He}^{3}$, Dorit Ron ${ }^{3}$, Matthew During ${ }^{4}$ and Peter W Kalivas' \\ 'Department of Neurosciences, Medical University of South Carolina, Charleston, SC, USA; ${ }^{2}$ Interdisciplinary Center for Neurosciences (IZN), \\ University of Heidelberg, Heidelberg, Germany; ${ }^{3}$ Department of Neurology, Gallo Research Center, University of California, San Francisco, \\ CA, USA; ${ }^{4}$ Department of Molecular Medicine and Pathology, University of Auckland, Auckland, New Zealand
}

\begin{abstract}
Homer proteins modulate neuroplasticity in excitatory synapses and are dynamically regulated by cocaine. Whereas acute cocaine elevates immediate-early gene (short) isoforms of Homerl in the nucleus accumbens, withdrawal from repeated cocaine administration downregulates the expression of constitutive Homerl isoforms. The present study determined whether or not this downregulation in constitutive Homer expression in the accumbens is necessary for enduring alterations in cocaine-induced changes in the brain and behavior. The long vs short Homer isoforms were overexpressed in the rat nucleus accumbens during drug abstinence, and the adaptations elicited by repeated cocaine on glutamate transmission and motor behavior were measured. It was found that both chronic and acute overexpression of constitutive, but not short, Homer isoforms abolished cocaine-induced sensitization of locomotor hyperactivity and prevented the development of glutamate abnormalities in the accumbens, including the reduction in basal extracellular glutamate content and the sensitized glutamate response to a subsequent cocaine challenge injection. Together, these data indicate that the enduring reduction of long Homer isoforms in the nucleus accumbens of cocaine-withdrawn rats is necessary for the expression of cocaine-induced neuroplasticity.

Neuropsychopharmacology (2006) 31, 768-777. doi:I0.1038/sj.npp. I 300890; published online I4 September 2005
\end{abstract}

Keywords: cocaine; Homer proteins; neuroplasticity; sensitization; glutamate; nucleus accumbens

\section{INTRODUCTION}

Homer proteins are encoded by three genes (Homer1-3), providing constitutively expressed, long isoforms (Homer1b/c/d, Homer2a/b, and Homer3) and immediateearly gene (short) isoforms (Homerla and aina-3) (cf, de Bartolomeis and Iasevoli, 2003). Both long and short Homer isoforms interact through an Ena/VASP1 homology (EVH1) domain with a long proline-rich motif located on Group 1 metabotropic glutamate receptors (mGluRs), inositol-1,4,5triphosphate (IP3) and ryanodine receptors, TRP cation channels and Shank (Brakeman et al, 1997; Hwang et al, 2003; Kammermeier et al, 2000; Kato et al, 1998; Tu et al, 1998, 1999; Xiao et al, 1998; Yuan et al, 2003). Long Homer isoforms contain a coiled-coil (CC) domain at their Cterminus that enables the cell membrane localization and clustering of glutamate receptors and proteins involved in

* Correspondence: Dr KK Szumlinski, Department of Psychology, University of California at Santa Barbara, Santa Barbara, CA 91।301996, USA, Tel: + I 805893 6|24, Fax: + I 805893 4303,

E-mail: szumlinski@psych.ucsb.edu

Received 7 June 2005; accepted 21 July 2005

Online publication: 4 August 2005 at http://www.acnp.org/citations/ Npp08040505037I/default.pdf their intracellular signaling cascades (Abe et al, 2003; Naisbitt et al, 1999; Rong et al, 2003; Shiraishi et al, 2003a, b). In contrast, short Homer1 isoforms lack the CCdomain and the ability to multimerize (Bottai et al, 2002; Xiao et al, 1998) and thus function as a natural dominant negative of Homer multimers to influence synaptic plasticity (Brakeman et al, 1997; Hennou et al, 2003; Sala et al, 2003).

The levels of Homer isoforms are differentially regulated in the nucleus accumbens by cocaine; acute cocaine transiently elevates short Homer isoforms, while a reduction in long Homer isoforms is observed following withdrawal from repeated cocaine administration (Brakeman et al, 1997; Ghasemzadeh et al, 2003; Swanson et al, 2001). Highlighting the potential importance of Homer proteins in cocaine addiction, adaptations in the glutamatergic projection from the prefrontal cortex to the accumbens have been linked to the behavioral consequences of repeated cocaine administration, such as drug-seeking and locomotor sensitization (Wolf, 1998; Kalivas et al, 2005). Moreover, data derived from studies of Homer mutant mice demonstrate that Homer proteins modulate nucleus accumbens glutamate transmission in vivo (Szumlinski et al, 2004a). Akin to the neuroadaptations in glutamate 
reported for rats following either contingent or noncontingent repeated cocaine treatment (cf, Kalivas et al, 2005), drug-naïve Homer1 and Homer2 mutant mice exhibit an approximately $50 \%$ reduction in basal extracellular glutamate content in the accumbens, as well as an increased capacity of acute cocaine to elevate glutamate levels in this nucleus (Szumlinski et al, 2004a). Supporting the link between cortico-accumbens glutamate and cocaine behavioral sensitivity, both Homer1 and Homer2 mutant mice exhibit a cocaine 'presensitized' behavioral phenotype, characterized by shifts to the left in the dose-response function for both cocaine-induced locomotor hyperactivity and place conditioning (Szumlinski et al, 2004a). Moreover, the 'presensitized' behavioral and glutamate phenotype of Homer2 mutant mice is reversed by adeno-associated virus (AAV)-mediated over-expression of the Homer2b isoform in the accumbens (Szumlinski et al, 2004a). Collectively, these data point to an active role for long Homer isoforms in regulating sensitivity to both the behavioral and neurochemical effects of acute cocaine.

It remains to be determined whether or not nucleus accumbens Homer expression is actively involved in regulating well-established behavioral and neurochemical adaptations induced by repeated cocaine treatment. Thus, the present study compared the effects of overexpressing short and long Homer isoforms in the accumbens upon the expression of behavioral and neurochemical sensitization following withdrawal from repeated cocaine treatment. Based upon the results of earlier immunoblotting and Homer mutant mouse studies (Swanson et al, 2001; Szumlinski et al, 2004a), it was hypothesized that if the cocaine-induced reduction in long Homer isoform expression in the accumbens is necessary for the expression of cocaine-induced behavioral and glutamatergic adaptations. Thus, overexpression of long, but not short, Homer isoforms in the nucleus accumbens should prevent the expression of cocaine-induced behavioral sensitization neuroadaptations in glutamate transmission.

\section{MATERIALS AND METHODS}

\section{Animals}

Experimentally naïve male Sprague-Dawley rats (Harlan, Indianapolis, IN; weighing $250-275 \mathrm{~g}$ at the start of the experiment) were housed individually in polyethylene cages $\left(35 \times 30 \times 16 \mathrm{~cm}^{3}\right)$ in an AAALAC-approved animal facility. The colony rooms were temperature controlled $\left(25^{\circ} \mathrm{C}\right)$ and under a $12 \mathrm{~h}$ day- $12 \mathrm{~h}$ night cycle (lights off: 1900 hours). Food and water were available ad libitum. Rats were allowed to acclimatize to the colony room for 4-5 days following arrival. All treatment sessions occurred during the light phase of the day-night cycle, beginning at 1200 hours. All experimental protocols were approved by the Institutional Animal Care and Use Committee of the Medical University of South Carolina and were consistent with the guidelines of the NIH Guide for Care and Use of Laboratory Animals (NIH Publication No. 80-23, revised 1996).

\section{Drugs}

Cocaine hydrochloride (a generous gift from the National Institute on Drug Abuse) was dissolved in $0.9 \%$ sterile saline and saline served for the systemic control injections (volume $=1.0 \mathrm{ml} / \mathrm{kg}$ ). For the no net-flux microdialysis study, glutamate (Sigma-RBI Chemical Co., Natick, MA) was dissolved in microdialysis buffer $(\mathrm{pH}=7.4)$ for infusion via the microdialysis probe.

\section{Surgery}

Using ketamine $(100 \mathrm{mg} / \mathrm{kg})$ and xylazine $(3 \mathrm{mg} / \mathrm{kg})$ anesthesia, microdialysis guide cannluae (20 gauge, $20 \mathrm{~mm}$, Plastics One) were implanted $3 \mathrm{~mm}$ over the nucleus accumbens using the following coordinates: AP: $+1.1 \mathrm{~mm}$; ML: $\pm 2.5 \mathrm{~mm}$; DV: $-4.7 \mathrm{~mm} ; 6^{\circ}$ angle from vertical (Paxinos and Watson, 1986). The AP and ML coordinates are relative to bregma and all DV coordinates are relative to the surface of the skull. The guide cannulae were fixed to the skull with four stainless-steel skull screws (Small Parts, Roanoke, VA) and dental acrylic and dummy cannulae (26 gauge, $20 \mathrm{~mm}$, Plastics One) were inserted to prevent guide cannulae occlusion. Animals were monitored for changes in health for at least 5 days prior to experimental manipulations.

\section{Construction of TAT-Fusion Protein}

Mouse full-length Homer 2a was amplified from pRK5-H2a (a generous gift from Dr Paul Worley at John Hopkins University School of Medicine) by PCR with the primers: upstream 5'-GCG GCC GCC CAT GGT TAT GGG AGA AGA GCC CAT CTT CAC-3' (with an extra NocI site) and downstream 5'-AAG GCC GGA ATT CTT ATC TAG TTA TCT GTG CCT AAC TTG-3' (with an extra EcoRI site) and recombined into pGEM-T vector (Promega). pGEM-H2a, was digested with $\mathrm{NcoI}$ and EcoRI to have the insert H2a which was then fused into the restriction sites NcoI and EcoRI of pTat-HA vector (a generous gift from Dr Steve F Dowdy at University of California, San Diego School of Medicine) which contains a $6 \times$ His tag. Tat-H2a was expressed in Escherichia coli as described previously (Nagahara et al, 1998; He et al, 2002). Bacterial culture $(500 \mathrm{ml})$ was homogenized in $20 \mathrm{ml}$ of lysis buffer ( $8 \mathrm{M}$ urea, $200 \mathrm{mM} \mathrm{NaCl}$, and $20 \mathrm{mM}$ HEPES $\mathrm{pH} 8.0$ ) followed by sonication for $2 \mathrm{~min}$. The homogenate was clarified by centrifugation at $4{ }^{\circ} \mathrm{C}$ for $30 \mathrm{~min}$ and purified by incubation with $\mathrm{Ni}^{2+}$-nitrilotriacetic acid agarose beads at $4{ }^{\circ} \mathrm{C}$ for $2 \mathrm{~h}$ while shaking. The beads were washed three times with $>6$ volumes of lysis buffer containing $20 \mathrm{mM}$ imidazole and then eluted with $500 \mathrm{mM}$ imidazole in the lysis buffer. The eluate was dialyzed against the buffer with gradually decreased urea until no urea. After that, Tat-Homer 2a was dialyzed twice against PBS plus $10 \%$ glycerol. The protein concentration was determined by using BCA reagent (Pierce Biochemicals). The construct of Tat-Kip ${ }^{27}$ was a generous gift from Dr Steve Dowdy and Tat-Kip ${ }^{27}$ was prepared following the same procedure.

\section{Construction of AAV}

The rat Homer1a, Homer1c, and Homer2b coding sequences were amplified using whole-brain cDNA, and the PCR was product expressed as an $\mathrm{N}$-terminal fusion protein with the hemagglutinin (HA)-tag in a rAAV backbone containing 
the $1.1 \mathrm{~kb} \mathrm{CMV}$ enhancer/chicken-actin (CBA) promoter, 800 bp human interferon scaffold attachment region (SAR) inserted 5_ of the promoter, the woodchuck post-transcriptional regulatory element (WPRE) and the bovine growth hormone polyA flanked by inverted terminal repeats (AAVHomer1a, AAV-Homer1c, and AAV-Homer2b). The same AAV-CBA-WPRE-bGH backbone encoding the enhanced green fluorescent protein (EGFP) was used as control (AAVGFP). AAV pseudotyped vectors (virions containing a $1: 1$ ratio of AAV1 and AAV2 capsid proteins with AAV2 ITRs were generated as described (Hauck et al, 2003). Briefly, HEK 293 cells were transfected with the AAV cis plasmid, the AAV1 (pH21) and AAV2 (pRV1) helper plasmids (pF6) and the adenovirus helper plasmid by standard calcium phosphate transfection methods. At $48 \mathrm{~h}$ after transfection, cells were harvested and the vector purified using heparin affinity columns as described (During et al, 2003). Genomic titers were determined using the Prism 7700 sequence detector system (Applied Biosystems, Foster City, CA) with primers designed to WPRE as previously described (Clark et al, 1999).

\section{AAV and TAT Infusion}

AAVs carrying the cNDA for Homerla, Homer1c, and Homer $2 b$ or enhanced green fluorescent protein (GFP) as a control were constructed as described previously (Klugmann et al, 2005; Szumlinski et al, 2004a). AAV infusion procedures were similar to those employed previously in mice (Szumlinski et al, 2004a, 2005b). In brief, rats were lightly restrained for a bilateral infusion of an $A A V$, conducted at a rate of $0.05 \mu \mathrm{l} / \mathrm{min}$ for $5 \mathrm{~min}$ (total volume $=0.25 \mu \mathrm{l} /$ side). Infusions were administered via injector cannulae (33 gauge, $22 \mathrm{~mm}$ in length, fitted into 24-gauge wire tubing, $20 \mathrm{~mm}$ in length). During infusion, rats were allowed to freely locomote in the home cage. Following infusion, the injectors were removed, the dummy cannulae were replaced and rats were monitored for changes in health for a period of 3 weeks prior to testing. TAT-fusion proteins were generated as described previously (Vagts et al, 2003), and intra-accumbens microinjection of TAT fusion proteins was conducted similar to the AAV infusion with the exception that infusion occurred at a rate of $0.25 \mu \mathrm{l} / \mathrm{min}$ for $1 \mathrm{~min}$ (total volume $=0.25 \mu \mathrm{l} / \mathrm{side}$ ) and infusion was conducted $30 \mathrm{~min}$ prior to testing. As a control for Tat-Homer2a, a Tat fusion with the cell cycle protein Kip was used as described previously (Vagts et al, 2003).

\section{Locomotor Sensitization}

Locomotor activity was monitored in a noncolony room containing 24 Plexiglas activity chambers $\left(22 \times 43 \times 33 \mathrm{~cm}^{3}\right)$ (Omnitech Electronics, Columbus, OH). A series of 16 photobeams (eight on each horizontal axis) tabulated horizontal movements and estimated the total distance traveled by the animal (in $\mathrm{cm}$ ). These chambers were interfaced to a Digiscan monitor (Omnitech Electronics, Columbus, $\mathrm{OH}$ ) and IBM PC computers provided automated recording of motor behavior. Locomotor studies commenced with a day of habituation, in which rats were placed into the activity chambers for $60 \mathrm{~min}$. Rats were injected with saline intraperitoneally (i.p.) and behavior was recorded for an additional $2 \mathrm{~h}$. On injections 1 and 7 of repeated treatment, animals were treated in an identical manner as described for the habituation day with the exception that animals were randomly assigned to receive an i.p. injection of cocaine $(15 \mathrm{mg} / \mathrm{kg}$, i.p.) or saline. On injections 2-6, rats were injected with either cocaine $(30 \mathrm{mg} / \mathrm{kg}$, i.p.) or saline, as appropriate, but injections occurred in the home cage. Following injection 7, drug treatment was withdrawn for 3 weeks and a test for sensitization was conducted in the activity chambers, in which all rats received a challenge injection of cocaine (15 mg/kg, i.p.).

For the study investigating the effects of AAV infusion upon the expression of locomotor sensitization, AAVs carrying GFP, Homer1a, Homer1c or Homer2b were infused the day following the seventh cocaine/saline injection. Given possible nonspecific consequences of long-term overexpression by AAV transfection, accumbens cells were also transiently transfected by an acute microinjection of Homer2a fused to the membrane permeability domain of Tat-HIV $30 \mathrm{~min}$ prior to the cocaine challenge injection administered following 3 weeks withdrawal.

\section{In Vivo Microdialysis Procedures}

Microdialysis probes (24 gauge; $23 \mathrm{~mm}$ in length incl. 1.5$2.0 \mathrm{~mm}$ active membrane) were constructed as described previously (Szumlinski et al, 2004b). Both conventional and no net-flux microdialysis sessions were conducted 3 weeks following the end of repeated cocaine/saline treatment and AAV infusion. For both microdialysis studies, microdialysis probes were inserted unilaterally into the nucleus accumbens and perfused overnight (at least $12 \mathrm{~h}$ prior to sample collection) at a rate of $0.1 \mu \mathrm{l} / \mathrm{min}$ with a microdialysis buffer $(5 \mathrm{mM}$ glucose, $2.5 \mathrm{mM} \mathrm{KCl}$, $140 \mathrm{mM} \mathrm{NaCl}, 1.4 \mathrm{mM} \mathrm{CaCl}_{2}, 1.2 \mathrm{mM} \mathrm{MgCl}_{2}, \quad 0.15 \%$ phosphate-buffered saline, $\mathrm{pH}$ 7.4). Probe insertion was counterbalanced across all treatment groups to reduce asymmetry confounds (Glick and Carlson, 1989). The following morning ( $\sim 0900$ hours), the flow rate was increased to $2.0 \mu \mathrm{l} / \mathrm{min}$ for at least $2 \mathrm{~h}$ prior to sample collection. For conventional microdialysis, dialysate was collected in $20-\mathrm{min}$ fractions into $10 \mu \mathrm{l}$ of preservative (4.76 $\mathrm{mM}$ citric acid, $150 \mathrm{mM} \mathrm{NaH}_{2} \mathrm{PO}_{4}, 50 \mu \mathrm{M}$ EDTA, $3 \mathrm{mM}$ sodium dodecyl sulfate, $10 \%$ methanol (v/v), 15\% acetonitrile (v/v), $\mathrm{pH} 5.6)$ for $2 \mathrm{~h}$, rats were injected i.p. with $15 \mathrm{mg} / \mathrm{kg}$ cocaine and sample collection continued for an additional $3 \mathrm{~h}$. For no net-flux microdialysis, increasing concentrations of glutamate $(2.5,5$ and $10 \mu \mathrm{M})$ were infused via the microdialysis probe for $1 \mathrm{~h}$ at each concentration. Dialysate was collected in 20-min intervals and the last two dialysate samples per concentration were used in the statistical analysis of the data.

\section{HPLC Analysis of Glutamate and Dopamine}

Glutamate in the dialysis sample was measured using a high-pressure liquid chromatography (HPLC) system with fluorescent detection. The mobile phase consisted of $13 \%$ acetylnitrile (v/v), $100 \mathrm{mM} \mathrm{NaH}{ }_{2} \mathrm{PO}_{4}, 0.1 \mathrm{mM}$ EDTA, pH 6.0. A reversed-phase column $(10 \mathrm{~cm}, 3 \mu \mathrm{m}$ ODS; Bioanalytical Systems, West Lafayette, IN) was used to separate the amino 
acids, and precolumn derivatization of amino acids with $o$-phthalaldehyde was performed using an ESA Model 540 autosampler. Glutamate was detected by a fluorescence spectrophotometer (LINEAR FLOUR LC 305, from ESA Inc.) using an excitation wavelength of $336 \mathrm{~nm}$ and an emission wavelength of $420 \mathrm{~nm}$. Glutamate content in each sample was analyzed by peak height and was compared with an external standard curve for quantification. Dopamine in the dialysate sample was measured using a HPLC system with electrochemical detection. The mobile phase consisted of $4.76 \mathrm{mM}$ citric acid, $150 \mathrm{mM} \mathrm{NaH} \mathrm{PO}_{4}, 50 \mu \mathrm{M}$ EDTA, $3 \mathrm{mM}$ sodium dodecyl sulfate, $10 \%$ methanol (v/v), 15\% acetylnitrile $(\mathrm{v} / \mathrm{v})$ at a $\mathrm{pH}=5.6$. Dopamine was separated using a reversed-phase column $(10 \mathrm{~cm}, \mathrm{C} 18$; Bioanalytical Systems, West LaFayette, IN) and oxidized/reduced using coulometric detection (Coulochem II, ESA Inc., Bedford, MA). Three electrodes were used: a preinjection port guard cell $(+0.1 \mathrm{~V})$ to oxidize the mobile phase, an oxidation analytical electrode $(\mathrm{E} 1,-0.075 \mathrm{~V})$, and a reduction analytical electrode $(\mathrm{E} 2,+0.3 \mathrm{~V})$. The area under curve of the dopamine peaks was measured with ESA 501 Chromatography Data System and the dopamine values were compared with an external standard curve for quantification.

\section{Verification of Transfection}

Rats were euthanized and their brains removed and placed in a $10 \%$ formalin solution. After fixation, the brains were sectioned along the coronal plane on a vibratome at the level of the nucleus accumbens $(100 \mu \mathrm{m}$; AP: +2.2 to $1.0 \mathrm{~mm}$, relative to bregma), according to the atlas of Paxinos and Watson (1986). Sections from AAV-Homer or Tat-Homer infused rats were stained with an antibody against the HA tag using standard immunocytochemical techniques as described previously for rats and mice (Klugmann et al, 2005; Szumlinski et al, 2004a, 2005b) and examined for transfection under a light microscope. Sections from AAV-GFP infused rats were examined for cellular transfection using a fluorescent microscope. Only rats whose injector cannulae were located within the boundaries of the nucleus accumbens (core or shell regions) and that exhibited cellular transfection were included in the statistical analysis.

\section{Statistical Analyses}

All behavioral and conventional microdialysis data were analyzed using analyses of variance (ANOVA). The data were analyzed using an AAV (GFP, Homerla, Homerlc, and Homer2b) or TAT (GFP $v s$ Homer2a) $\times$ Cocaine Treatment (saline $v s$ cocaine) ANOVA with repeated measures on the injection factor (injection $1 v s$ injection 7) or the Time factor (for locomotor sensitization: 12, 10-min bins; for neurochemical sensitization: 12, 20-min bins). For the no net-flux microdialysis experiment, linear regression analyses were conducted individually for each rat and the slope of the linear region and the $y$-intercept were determined. The slopes and $y$-intercepts were compared using an AAV $\times$ Repeated Treatment ANOVA. If significant interactions were found, the interactions were decomposed, followed by LSD post hoc comparisons.

\section{RESULTS}

\section{Transfection by AAV or Tat-Fusion Proteins}

Two transfection methods were employed to introduce Homer proteins into the nucleus accumbens, AAV transfection (Figure 1a) and fusion of Homer to the membrane permeability motif of HIV-Tat (Figure 1b). Transfected protein was distinguished from endogenous Homer by staining for the HA tag included in the microinjected protein. Labeling of both soma and fibers was produced, although the AAV transfection appeared to more efficiently label fibers than Tat-Homer. In both cases, the amount of tissue transfection was limited to $<1 \mathrm{~mm}$ from the tip of the infusion site (Figure 1).

\section{Effects of Homer Overexpression upon Cocaine-Induced Locomotor Sensitization Following Withdrawal}

Intra-accumbens AAV infusion made on the day following the end of repeated cocaine administration significantly altered the locomotor response elicited by a cocaine injection administered 3 weeks later (Figure 2) (Virus effect: $\mathrm{F}(3,70)=2.84, p=0.04$; Cocaine $\times$ Virus: $\mathrm{F}(3,70)=$ $2.26, p<0.0001$; Cocaine $\times$ Virus $\times$ Time: $\mathrm{F}(33,770)=0.81$, $p=0.77)$. The presence of sensitization was identified using planned comparisons between the repeated saline- and repeated cocaine-treated rats within each AAV group and
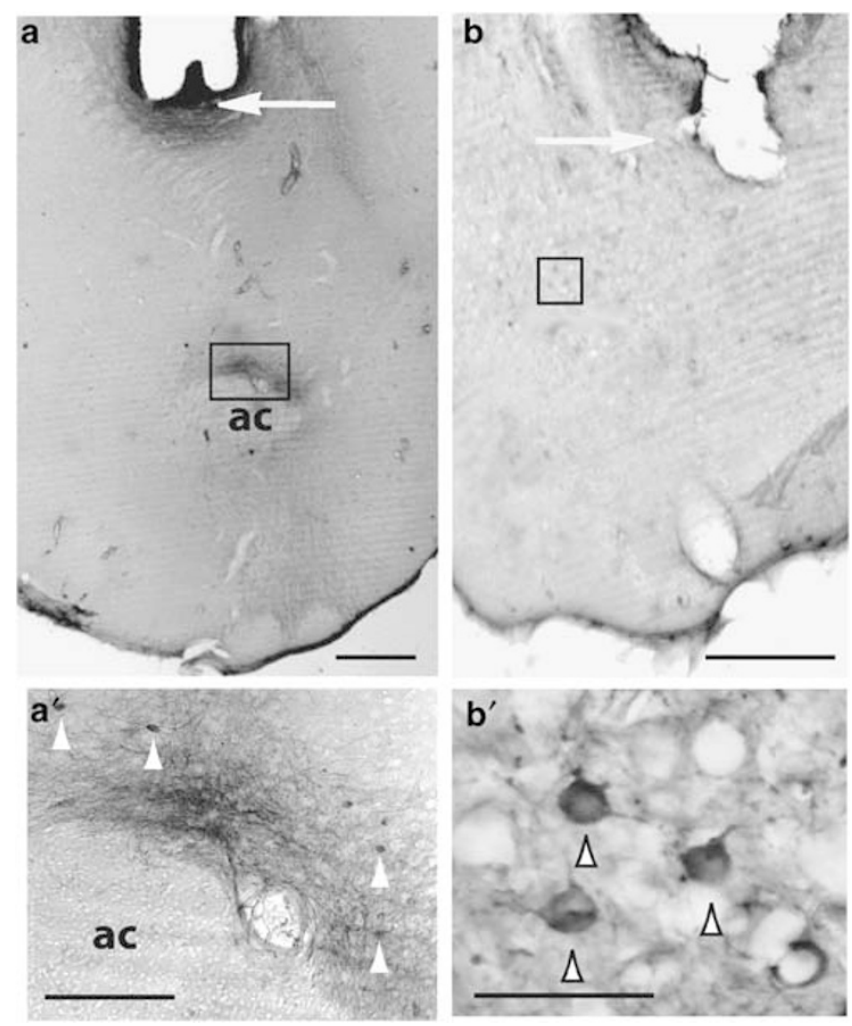

Figure I Transfection of accumbens cells by AAV and TAT. a,a', representative immuno-staining for HA-tagged Homers at 3 weeks following AAV-Homerla infusion. b, b', representative immuno-staining for HA-tagged Homer2a at I h following intra-accumbens (ac-anterior commissure, arrows refer to neurons or bottom of guide cannula track). $\operatorname{Bar}=0.5 \mathrm{~mm}(\mathrm{a}), 0.2 \mathrm{~mm}\left(\mathrm{a}^{\prime}\right), 0.5 \mathrm{~mm}(\mathrm{~b}), 0.1 \mathrm{~mm}\left(\mathrm{~b}^{\prime}\right)$. 

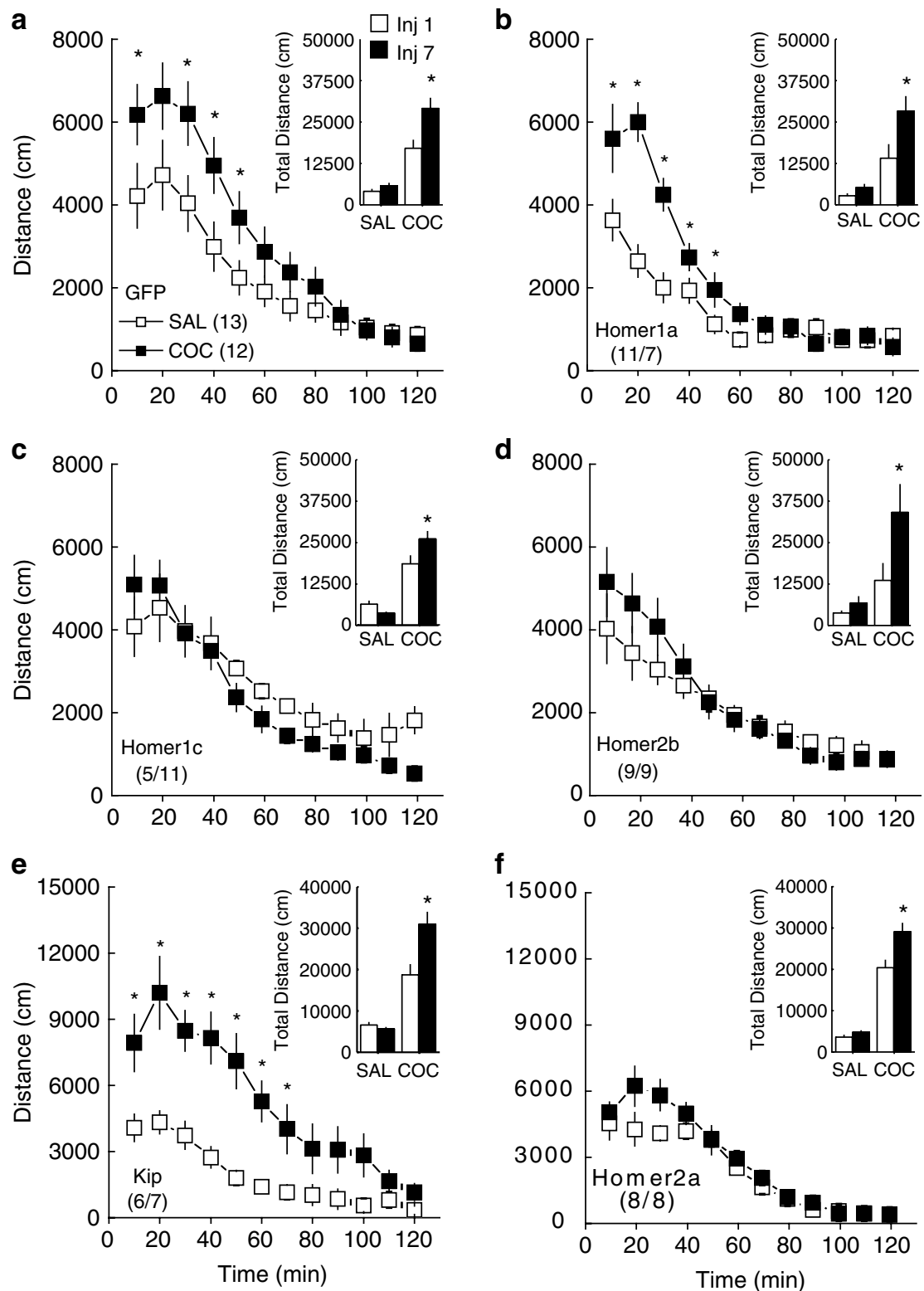

Figure 2 Overexpression of long-form Homers blocks cocaine-induced locomotor sensitization. Daily injections of cocaine for I week produce locomotor sensitization (insets in panels $\mathrm{a}-\mathrm{f}$ ). (a-d) Cocaine challenge injection ( $15 \mathrm{mg} / \mathrm{kg}$, i.p.) administered after accumbens transfection with AAVHomer I c or AAV-Homer2b blocks motor sensitization. (e, f) Cocaine challenge after cellular transduction with Tat-Homer2a, but not Tat-Kip, blocks motor sensitization. Data shown as mean \pm SEM distance traveled (cm; supplemental methods) and the number of animals indicated in parentheses (Saline/ Cocaine). Data were evaluated using a three-way ANOVA (supplemental methods). ${ }^{*} p<0.05$, comparing repeated cocaine and saline within each panel.

revealed sensitization in the cocaine-treated groups pretreated with AAV-GFP (Figure 2a) (Cocaine $\times$ Time: $\mathrm{F}(11,264)=3.98, \quad p<0.0001)$ and with AAV-Homerla (Figure 2b) (Cocaine $\times$ Time: $\mathrm{F}(11,176)=9.83, p<0.0001)$. In contrast, no sensitization was apparent in cocaine-treated animals pretreated with either AAV-Homer1c (Figure 2c) (Cocaine $\times$ Time: $\mathrm{F}(11,154)=1.25, \quad p=0.26$ ) or AAVHomer2b (Figure 2d) (Cocaine $\times$ Time: $\mathrm{F}(11,176)=1.65$, $p=0.08)$.

Statistical analysis of the data from injections 1 and 7 of repeated treatment revealed that prior to AAV infusion all groups of animals showed significant behavioral sensitization (Figure 2a-d, insets) (Cocaine $\times$ Injection: $\mathrm{F}(1,70)=27.30$, $p<0.0001$; Cocaine $\times$ Injection $\times$ Virus: $\mathrm{F}(3,70)=0.58, p=0.63)$. Moreover, group differences were not observed regarding the total distance traveled during the 60 -min habituation period preceding the test for sensitization (Cocaine effect: $p=0.66$; Virus effect: $p=0.43$; Cocaine $\times$ Virus: $p=0.19$ ) (data not shown), indicating that AAV-Homer1c or AAVHomer2b effects on cocaine sensitization were not attributable to a priori differences in spontaneous or cocaineinduced effects on locomotion.

\section{Effects of TAT-Mediated Overexpression of a Long Homer Isoform upon Locomotor Sensitization Following Withdrawal}

Nonspecific consequences may have occurred as a result of the long-term overexpression of Homers by AAV transfection. Thus, the effect of acute upregulation of Homer2a 
was examined by intra-accumbens infusion of Homer2a fused to the membrane permeability motif of Tat-HIV (Vagts et al, 2003; Bowers et al, 2003). At 3 weeks following daily administration of saline or cocaine, rats were transiently transfected by an acute microinjection of Tat fusion proteins, $30 \mathrm{~min}$ prior to the cocaine challenge injection. Akin to results obtained with AAV infusion, Tat-Homer2a infusion altered the amount of locomotion expressed by repeated cocaine-treated rats on test day (Cocaine effect: $\mathrm{F}(1,29)=25.46, \quad p<0.0001$; Tat effect: $\mathrm{F}(1,29)=10.37, p=0.003$; Cocaine $\times$ Tat: $\mathrm{F}(1,29)=13.75$, $p=0.001$; Cocaine $\times$ Tat $\times$ Time: $\mathrm{F}(11,319)=1.22, p=0.27)$. Planned comparisons revealed behavioral sensitization in cocaine-treated Tat-Kip rats (Figure 2e) (Cocaine $\times$ Time: $\mathrm{F}(11,176)=3.01, \quad p=0.001)$, but not in cocaine-treated Tat-Homer2a rats (Figure $2 \mathrm{f})($ Cocaine $\times$ Time: $\mathrm{F}(11,143)=$ $1.35, p=0.20$ ). Again, the effect of Tat-Homer2a upon the expression of behavioral sensitization was not reflected by a priori differences in the development of sensitization between Tat treatment groups (Figure $2 \mathrm{e}-\mathrm{f}$, insets) (Cocaine $\times$ injection: $\mathrm{F}(1,29)=13.40, p=0.001$; Cocaine $\times$ Injection $\times$ Tat: $\mathrm{F}(1,29)=0.25, p=0.72$ ) or in locomotor activity during the $60-\mathrm{min}$ habituation period preceding the test (Cocaine effect: $p=0.72$; Tat effect: $p=0.24$; Cocaine $\times$ Tat: $p=0.11$ ) (data not shown).

\section{Effects of Homer Overexpression upon the Expression of Cocaine-Induced Adaptations in Glutamate}

The in vivo extracellular levels of glutamate and dopamine were measured via a microdialysis probe inserted into the nucleus accumbens. An enduring reduction in basal levels of extracellular glutamate in the accumbens is produced by withdrawal from cocaine and contributes to the reinstatement of cocaine-seeking (Baker et al, 2003). Using no-net-flux microdialysis, the extracellular concentration of glutamate was determined at 3 weeks following AAV administration (Figure 3). AAV infusion significantly altered the change in basal extracellular levels of accumbens glutamate observed in cocaine-treated rats $(y=0$ : Cocaine effect: $\mathrm{F}(1,58)=52.25, p<0.0001$; AAV $\times$ Cocaine: $\mathrm{F}(3,58)=$ $10.06, p<0.0001)$. Decomposition of the significant two-way ANOVA revealed that AAV-Homerlc (Cocaine effect: $\mathrm{F}(1,12)=0.05, \quad p=0.83)$ and AAV-Homer2b $(\mathrm{F}(1,16)=$ $3.31, p=0.09$ ) reversed cocaine-induced decreases in basal extracellular glutamate, while transfection with AAV-GFP $(\mathrm{F}(1,15)=97.44, p<0.0001)$ or AAV-Homerla $(\mathrm{F}(1,12)=$ $87.41, p<0.0001$ ) was ineffective in this regard (Figure 3 ). None of the AAV treatments altered the slopes of the linear regressions (Cocaine effect: $\mathrm{F}(1,58)=11.03, p=0.002$; AAV $\times$ Cocaine: $\mathrm{F}(3,58)=1.64, p=0.09)$, indicating that $\mathrm{AAV}$ infusion did not alter glutamate reuptake processes. Similar effects of AAV infusion were observed upon basal extracellular glutamate levels when assessed using conventional microdialysis techniques (Table 1 ) (Cocaine $\times$ AAV: $\mathrm{F}(3,50)=4.34, p=0.009)$.

Another cocaine-induced adaptation in glutamate transmission linked to behavioral sensitization and the reinstatement of cocaine-seeking is increased releasibility of glutamate, an adaptation resulting partly from cocaineinduced reductions in glutamate tone upon inhibitory metabotropic glutamate autoreceptors (cf, Kalivas et al,

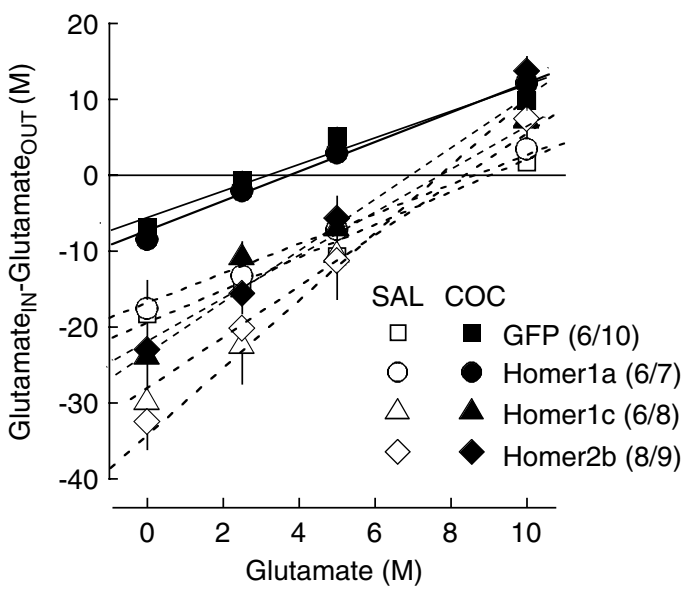

Figure 3 Over-expression of long-form Homers reverses cocaineinduced reduction in accumbens glutamate content. The reduction in accumbens basal glutamate content $(y=0)$ observed in cocaine-treated rats at three weeks withdrawal from cocaine treatment was reversed by an intra-accumbens infusion of AAV-Homerlc or AAV-Homer2b, but not by infusions of AAV-GFP or AAV-Homer la. Data shown as mean \pm SEM, and number of animals indicated in parentheses and were analyzed using a two-way ANOVA, followed by LSD post hoc tests.

Table I Effects of Accumbens AAV Transfection Upon Basal Extracellular Levels of Glutamate and Dopamine as Assessed by Conventional In Vivo Microdialysis at 3 weeks Withdrawal from Repeated Cocaine Treatment

\begin{tabular}{|c|c|c|c|c|}
\hline & \multicolumn{2}{|c|}{ Glutamate (pmol/sample) } & \multicolumn{2}{|c|}{ Dopamine (fmol/sample) } \\
\hline & Saline & Cocaine & Saline & Cocaine \\
\hline GFP & $109.2 \pm 7.1(6)$ & $34.1 \pm 6.3(10)^{*}$ & $19.8 \pm 3.2(6)$ & $26.7 \pm 3.3(8)$ \\
\hline Homerla & $118.6 \pm 12.6(5)$ & $53.4 \pm 4.7(7)^{*}$ & $21.3 \pm 9.9(5)$ & $23.5 \pm 3.8(6)$ \\
\hline Homerlc & $111.0 \pm 9.5(6)$ & $87.1 \pm 10.0(10)$ & $27.2 \pm 7.0(6)$ & $29.2 \pm 4.4(8)$ \\
\hline Homer2b & $101.7 \pm 9.6(5)$ & $74.2 \pm 14.8(9)$ & $19.1 \pm 4.7(5)$ & $23.9 \pm 3.1(8)$ \\
\hline
\end{tabular}

Data for each neurotransmitter were analyzed using a two-way ANOVA. $* P<0.05$ vs respective saline group.

2005). Correspondingly, transfection with AAVs carrying the long Homer isoforms that reversed the effect of repeated cocaine upon basal levels of glutamate (Figure 3; Table 1) also prevented the increase in extracellular glutamate elicited by a cocaine challenge administered after 3 weeks of withdrawal (Figure 4a) (Cocaine $\times$ Virus $\times$ Time: $\mathrm{F}(33,550)=$ 2.24, $p<0.0001)$. Decomposition of the significant threeway ANOVA along the AAV factor revealed significant glutamate sensitization in cocaine-treated rats infused with AAV-GFP (Cocaine $\times$ Time: $\mathrm{F}(11,154)=3.17, p=0.001$ ) or AAV-Homerla (Cocaine $\times$ Time: $\mathrm{F}(11,110)=3.23$, $p=0.001)$, but not in cocaine-treated rats infused with AAV-Homerlc (Cocaine $\times$ Time: $\mathrm{F}(11,154)=1.35, p=0.20)$ or AAV-Homer2b (Cocaine $\times$ Time: $\mathrm{F}(11,132)=0.84, p=0.60)$. As was observed for behavior, none of the AAV transfections altered the effect of acute cocaine on extracellular glutamate (compare saline groups in Figure 4a). 

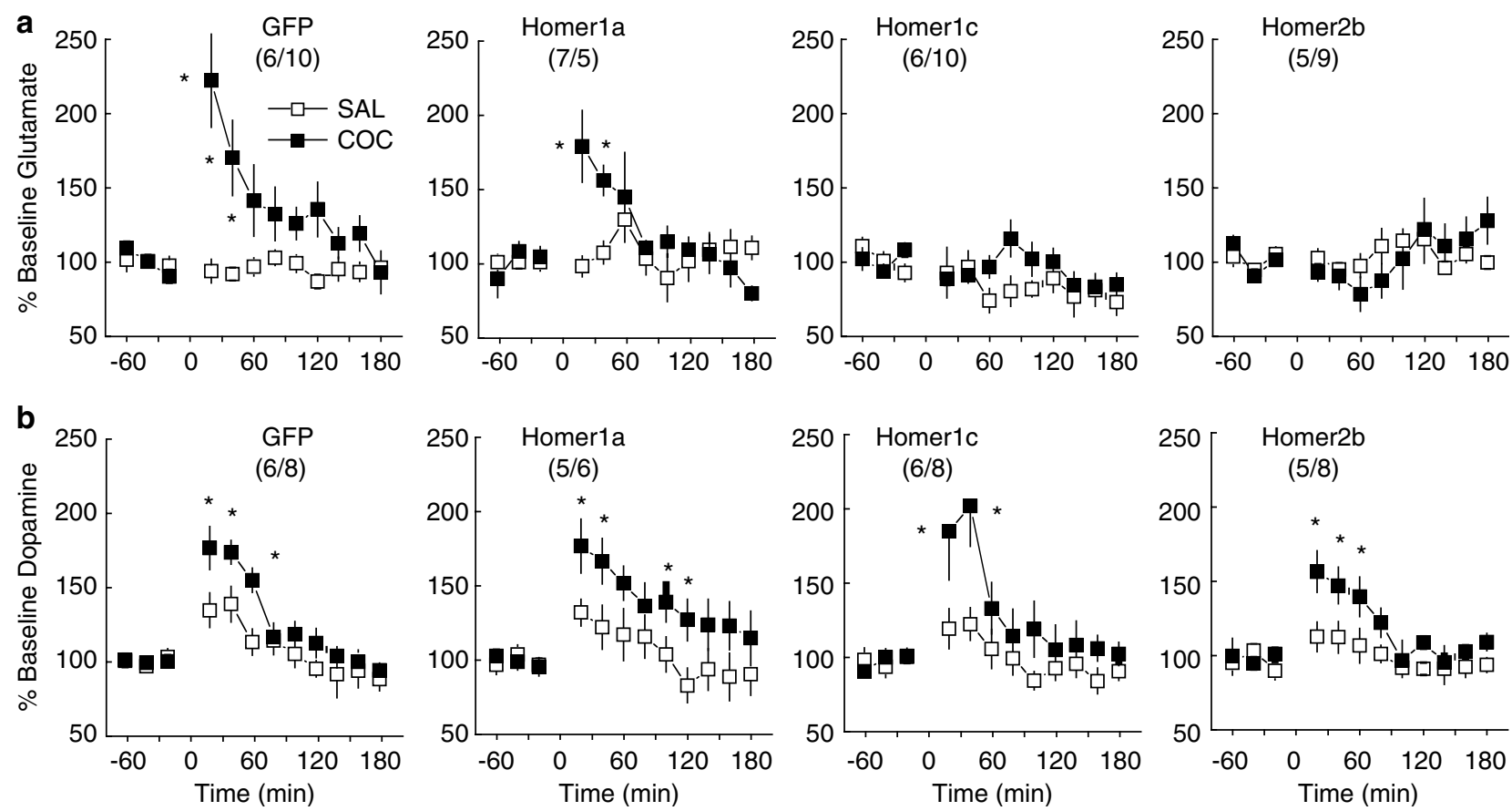

Figure 4 Over-expression of long-form Homers reverses cocaine-induced adaptations in glutamate releasability. (a) Intra-accumbens infusion of AAVHomerlc or AAV-Homer2b prevented the augmented increase in extracellular glutamate elicited by a cocaine injection administered following 3 weeks withdrawal. (b) In contrast to the effects observed for glutamate, AAV transfection did not block cocaine-induced increases in extracellular dopamine. Data shown as mean \pm SEM, and number of animals indicated in parentheses. Data were transformed to percent change from the basal levels (Table I), and were analyzed using a three-way ANOVA. *p $<0.05$, comparing repeated cocaine and saline within each panel.

\section{Effects of Homer Overexpression on Cocaine-Induced Dopamine Sensitization Following Withdrawal}

Akin to glutamate, withdrawal from repeated cocaine augments the capacity of a cocaine challenge to elevate extracellular dopamine in the accumbens (eg, Robinson and Berridge, 2003). However, none of the AAV constructs altered the acute or sensitized cocaine-induced increases in extracellular dopamine (Figure 4b). This was confirmed statistically by a significant Cocaine $\times$ Time interaction $(\mathrm{F}(11,473)=3.83, p<0.0001)$ but no significant interactions with the AAV factor (Cocaine $\times$ AAV: $F(3,43)=0.26$, $p=0.88$; AAV $\times$ Time: $\mathrm{F}(33,473)=0.59, p=0.97$; Cocaine $\times$ $\mathrm{AAV} \times$ Time: $\mathrm{F}(33,473)=0.37, p=1.0)$.

\section{DISCUSSION}

Alterations in corticofugal glutamate transmission have been implicated in mediating the long-term behavioral consequences of repeated cocaine, including behavioral sensitization and reinstatement of cocaine-seeking (Pierce and Kalivas, 1997; Wolf, 1998; Kalivas et al, 2005). Withdrawal from cocaine reduces the level of long-form Homerlb/c in the nucleus accumbens of rats, coincident with the manifestation of behavioral sensitization and abnormalities in accumbens glutamate (Swanson et al, 2001). Consistent with the above association between reduced accumbens long Homer isoform expression and cocaine-induced neuroplasticity, cocaine-naïve mice with null mutations of Homer2 exhibit glutamatergic abnormalities in the accumbens that mimic those observed in rats upon withdrawal from repeated cocaine administration
(Szumlinski et al, 2004a). Moreover, Homer2 mutant mice exhibit a 'presensitized' behavioral phenotype that is characterized by increased sensitivity to the psychomotoractivating and rewarding effects of cocaine (Szumlinski et al, 2004a). At least in the case of the mutant mice, the behavioral and neurochemical sensitivity to cocaine can be restored to wild-type levels by overexpressing the Homer2b splice variant in the accumbens, indicating an active role for this long Homer isoform in augmented sensitivity to acute cocaine (Szumlinski et al, 2004a). The present data extend the results of these earlier reports by demonstrating that overexpressing long-form Homer1 or Homer2 gene products antagonizes the consequences of withdrawal from repeated cocaine upon glutamate transmission and behavioral sensitization; thereby, pointing out the potential importance of cocaine-induced effects on long-form Homer1 in the sequelae of cellular adaptations responsible for the well-characterized glutamatergic and behavioral abnormalities produced by withdrawal from repeated cocaine exposure.

\section{Homer Proteins and the Regulation of Glutamate Transmission}

Homer proteins are constituents of a large complex of proteins that are localized to the postsynaptic density at glutamatergic synapses in the brain (cf, de Bartolomeis and Iasevoli, 2003; Fagni et al, 2002). Via an Ena/VASP1 Homology (EVH1) domain, both long and short Homer isoforms interact with a long proline-rich motif located the Group 1 mGluRs, mGluR1a, and mGluR5, inositol-1,4,5triphosphate (IP3) and ryanodine receptors, TRP cation 
channels and the NMDA receptor scaffolding protein Shank (Brakeman et al, 1997; Hwang et al, 2003; Kammermeier et al, 2000; Kato et al, 1998; Tu et al, 1998, 1999; Xiao et al, 1998; Yuan et al, 2003). Multimerization of long Homer isforms through their C-terminal CC-domains mediates the cell membrane localization and postsynaptic density clustering of glutamate receptors and proteins involved in their intracellular signaling cascades (Abe et al, 2003; Naisbitt et al, 1999; Rong et al, 2003; Shiraishi et al, 2003a, b). Moreover, long Homer isoform expression is also necessary for the normal formation of glutamatergic synapses during development (Shiraishi et al, 2004). The lack of effect by Homerla overexpression in the present study argues that it is the property of long Homer isoforms to cluster proteins and create cell-signaling microdomains via the CC-domain that is critical for the neuroadaptations produced by repeated cocaine administration.

Corresponding to the established role of Homer proteins in regulating the structure and function of excitatory synapses, mutations of either Homer1 or Homer2 produce a number of abnormalities in excitatory transmission in the accumbens, including a reduction in the function and total protein expression of mGluR $1 \mathrm{a}$, a reduction in the cell membrane localization of NR2 subunits, a reduction in the function and expression of the cystine-glutamate exchanger, as well as alterations basal extracellular glutamate levels and glutamate releasability (Szumlinski et al, 2004a, $2005 \mathrm{a}, \mathrm{b})$. The cystine-glutamate exchanger is the primary source of accumbens extracellular glutamate in vivo (Baker et al, 2002) and cocaine-induced downregulation of cystineglutamate exchange underlies the alterations in extracellular levels of glutamate and glutamate releasability observed following withdrawal from either contingent or noncontingent cocaine administration (Baker et al, 2003). Although it still remains to be determined precisely how Homer proteins interact with the cystine-glutamate exchanger or how postsynaptic scaffolding proteins influence presynaptic glutamate release, our finding that preventing the cocaineinduced reduction in long Homer isoforms reversed the effects of cocaine withdrawal upon extracellular glutamate content and glutamate releasability, points to a potential interaction between Homer and the cystine/glutamate exchanger in the expression of cocaine-induced glutamate neural pathologies relevant to addiction.

Intra-accumbens overexpression of Homer failed to alter basal extracellular dopamine levels and did not affect either the acute or the sensitized dopamine response to cocaine. This lack of an effect of Homer manipulation is consistent with data derived from Homer 1 or Homer 2 knockout mice, demonstrating no effect of either gene deletion upon basal extracellular levels of dopamine or cocaine-stimulated increases in dopamine in the accumbens (Szumlinski et al, 2004a). Collectively, these data further highlight the relative importance of glutamatergic adaptations in the enduring behavioral consequences of repeated cocaine (Kalivas et al, 2005).

\section{Homer Proteins and Behavioral Sensitivity to Drugs}

First described for acute cocaine (Brakeman et al, 1997), a growing number of studies demonstrate an enhancement within corticolimbic structures in the expression of mRNA encoding short Homer isoforms by acute exposure to psychoactive drugs (de Bartolomeis et al, 2002; Cochran et al, 2002; Fujiyama et al, 2003; Nichols et al, 2003; Nichols and Sanders-Bush, 2002; Polese et al, 2002). Although there is some evidence that the capacity of drugs of abuse to increase short Homer isoform expression is enduring (Ammon et al, 2003; Cochran et al, 2002) or persists throughout repeated drug administration (Ammon et al, 2003; Fujiyama et al, 2003), behavioral sensitization to methamphetamine is not coincident with an altered capacity of this drug to elevate the expression of short Homer isoforms (Fujiyama et al, 2003). Moreover, intraaccumbens infusions of either antisense oligonucleotides against Homer1 or AAVs overexpressing Homerla prevent the development of cocaine-induced behavioral sensitization due to an enhancement in the acute response to the drug (Bowers et al, 2003; Ghasemzadeh et al, 2003). Finally, the present data demonstrating that accumbens Homerla overexpression failed to alter either the behavioral or the neurochemical response to acute or repeated cocaine argues against a necessary role for alterations in accumbens expression of short-form Homers in the development and expression of drug-induced behavioral plasticity.

In contrast to the short isoforms, considerably more convergence exists regarding long Homer isoforms and behavioral sensitivity to drugs of abuse. Consistent with the effects of Homer1 downregulation by antisense oligonucleotides (Ghasemzadeh et al, 2003), both Homer1 and Homer 2 mutant mice exhibit increased sensitivity to the psychomotor-activating effects of cocaine, methamphetamine and dissociative anesthetic drugs (Szumlinski et al, 2004a, 2005a). As Homer1 encodes both short and long isoforms (Brakeman et al, 1997; Bottai et al, 2002), it is impossible to distinguish between the two Homer1 isoforms using Homer1 mutant mice exclusively. However, Homer2 encodes only long-form Homers (cf, de Bartolomeis and Iasevoli, 2003) and thus, the 'presensitized' behavioral phenotype of Homer 2 mutant mice can be attributed to missing long Homer isoforms. In support of this, intraaccumbens infusion of an AAV carrying the long Homer isoform Homer $2 b$ rescued the cocaine behavioral and neurochemical phenotype of Homer 2 mutant mice, confirming an active role for this long Homer isoform in the mediation of acute sensitivity to cocaine (Szumlinski et al, 2004a). Our observation that overexpressing Homer1b, Homer2a, or Homer2b in the accumbens all reversed the expression of cocaine-induced behavioral sensitization corroborates earlier correlational evidence for an inverse relationship between long Homer isoform expression in the accumbens and cocaine sensitization in rats (Swanson et al, 2001), and points to drug-induced reductions in long Homer isoform expression as a necessary cellular adaptation in the accumbens contributing to this form of behavioral plasticity.

\section{Conclusions}

Intra-accumbens overexpression of long, but not short, Homer isoforms during withdrawal from repeated cocaine prevented the reduced basal extracellular content and enhanced releasability of glutamate. Consistent with the 
hypothesized role of these glutamatergic adaptations in cocaine-induced behavioral changes (Kalivas et al, 2005), intra-accumbens overexpression of long, but not, short Homer isoforms prevented the expression of cocaineinduced behavioral sensitization. The present data reveal cocaine-induced regulation of long Homer isoforms as a core mechanism underlying the linkage between plasticity in glutamatergic projections to nucleus accumbens and certain behavioral consequences of repeated cocaine administration.

\section{ACKNOWLEDGEMENTS}

We acknowledge NIDA for the generous gift of cocaine. This work was supported, in part, by grants from NIDA (DA-03906, DA-14185) to PWK and funds provided by the State of California for medical research on alcohol and substance abuse through the University of California, San Francisco to DR. KKS was supported, in part, by a postdoctoral fellowship from the CIHR.

\section{REFERENCES}

Abe H, Misaka T, Tateyama M, Kubo Y (2003). Effects of coexpression with Homer isoforms on the function metabotropic glutamate receptor 1alpha. Mol Cell Neurosci 23: 157-168.

Ammon S, Mayer P, Riechert U, Tischmeyer H, Hollt V (2003). Microarray analysis of genes expressed in the frontal cortex of rats chronically treated with morphine and after naloxone precipitated withdrawal. Brain Res Mol Brain Res 112: 113-125.

Baker DA, McFarland K, Lake RW, Shen H, Tang XC, Toda S et al (2003). Neuroadaptations in cystine-glutamate exchange underlie cocaine relapse. Nat Neurosci 6: 743-749.

Baker DA, Xi ZX, Shen H, Swanson CJ, Kalivas PW (2002). The origin and neuronal function of in vivo nonsynaptic glutamate. J Neurosci 22: 9134-9143.

Bottai D, Guzowski JF, Schwarz MK, Kang SH, Xiao B, Lanahan A et al (2002). Synaptic activity-induced conversion or intronic to exonic sequence in Homer 1 immediate early gene expression. J Neurosci 22: 167-175.

Bowers MS, Lake RW, Rubinchik S, Dong JY, Kalivas PW (2003). Elucidation of Homer 1a function in the nucleus accumbens using adenovirus gene transfer technology. Ann NY Acad Sci 1003: 419-421.

Brakeman PR, Lanahan AA, O'Brien R, Roche K, Barnes CA, Huganir RL et al (1997). Homer: a protein that selectively binds metabotropic glutamate receptors. Nature 386: 221-223.

Clark KR, Liu X, McGrath JP, Johnson PR (1999). Highly purified recombinant adeno-associated virus vectors are biologically active and free of detectable helper and wild-type viruses. Hum Gene Ther 10: 1031-1039.

Cochran SM, Fujimura M, Morris BJ, Pratt JA (2002). Acute and delayed effects of phencyclidine upon mRNA levels of markers of glutamatergic and GABAergic neurotransmitter function in the rat brain. Synpase 46: 206-214.

de Bartolomeis A, Aloj L, Ambesi-Impiombato A, Bravi D, Curaco C, Muscettola G et al (2002). Acute administration of antipsychotics modulates Homer striatal gene expression differentially. Brain Res Mol Brain Res 98: 124-129.

de Bartolomeis A, Iasevoli F (2003). The Homer family and the signal transduction system at glutamatergic postsynaptic density: potential role in behavior and pharmacotherapy. Psychopharmacol Bull 37: 51-83.

During MJ, Young D, Baer K, Lawlor P, Klugmann M (2003). Development and optimization of adeno-associated virus vector transfer into the central nervous system. Methods Mol Med 76: 221-236.

Fagni L, Worley PF, Ango F (2002). Homer as both a scaffold and transduction molecule. Sci STKE 137: RE8.

Fujiyama K, Kajii Y, Hiraoka S, Nishikawa T (2003). Differential regulation by stimulants of neocortical expression of mrt1, arc, and homerla mRNA in the rats treated with repeated methamphetamine. Synapse 49: 143-149.

Ghasemzadeh MB, Permenter LK, Lake R, Worley PF, Kalivas PW (2003). Homer1 proteins and AMPA receptors modulate cocaine-induced behavioural plasticity. Eur J Neurosci 18: 1645-1651.

Glick SD, Carlson JN (1989). Regional changes in brain dopamine and serotonin metabolism induced by conditioned circling in rats: effects of water deprivation, learning and individual differences in asymmetry. Brain Res 504: 231-237.

Hauck B, Chen L, Xiao W (2003). Generation and characterization of chimeric recombinant AAV vectors. Mol Ther 7: 419-425.

He D-Y, Vagts AJ, Yaka R, Ron D (2002). Ethanol induces gene expression via nuclear compartmentalization of Receptor Activated C Kinase I. Mol Pharmacol 62: 272-280.

Hennou S, Kato A, Schneider EM, Lundstrom K, Gahwiler BH, Inokuchi K et al (2003). Homer-1a/Vesl-1S enhances hippocampal synaptic transmission. Eur J Neurosci 18: 811-819.

Hwang SY, Wei J, Westhoff JH, Ducan RS, Ozawa F, Volpe P et al (2003). Differential functional interaction of two Vesl/Homer protein isoforms with ryanodine receptor type 1: a novel mechanism for control of intracellular calcium signaling. Cell Calcium 34: 177-184.

Kalivas PW, Volkow N, Seamans J (2005). Unmanageable motivation in addiction: a pathology in prefrontal-accumbens glutamate transmission. Neuron 45: 647-650.

Kammermeier PJ, Xiao B, Tu JC, Worley PF, Ikeda SR (2000). Homer proteins regulate coupling of group I metabotropic glutamate receptors to $\mathrm{N}$-type calcium and M-type potassium channels. J Neurosci 20: 7238-7245.

Kato A, Ozawa F, Saitoh Y, Fukazawa Y, Sugiyama H, Inoduchi K (1998). Novel members of the Vesl/Homer family of PDZ proteins that bind metabotropic glutamate receptors. J Biol Chem 273: 23969-23975.

Klugmann M, Wymond Symes C, Leichtlein CB, Klaussner BK, Dunning J, Fong D et al (2005). AAV-mediated hippocampal expression of short and long Homer 1 proteins differentially affect cognition and seizure activity in adult rats. Mol Cell Neurosci. 28: 347-360.

Nagahara H, Vocero-Akbani AM, Snyder EL, Ho A, Latham DG, Lissy NA et al (1998). Transduction of full-length TAT fusion proteins into mammalian cells: TAT-p27Kip1 induces cell migration. Nat Med 4: 1449-1452.

Naisbitt S, Kim E, Tu JC, Xiao B, Sala C, Valtschanoff J et al (1999). Shank, a novel family of postsynaptic density proteins that binds to the NMDA receptor/PSD-95/GKAP complex and cortactin. Neuron 23: 569-582.

Nichols CD, Garcia EE, Sanders-Bush E (2003). Dynamic changes in prefrontal cortex gene expression following lysergic acid diethylamide administration. Brain Res Mol Brain Res 111: 182-188.

Nichols CD, Sanders-Bush E (2002). A single dose of lysergic acid diethylamide influences gene expression patterns within the mammalian brain. Neuropsychopharmacology 26: 634-642.

Paxinos G, Watson C (1986). The Rat Brain in Stereotaxic Coordinates. Academic Press: New York.

Pierce RC, Kalivas PW (1997). A circuitry model of the expression of behavioral sensitization to amphetamine-like psychostimulants. Brain Res Rev 25: 192-216.

Polese D, Amato de Serpis A, Ambesi-Impiombato A, Muscettola G, de Bartolomeis A (2002). Homer la gene expression 
modulation by antipsychotic drugs: involvement of the glutamate metabotropic system and effects of D-cycloserine. Neuropsychopharmacology 27: 906-913.

Robinson TE, Berridge KC (2003). Addiction. Annu Rev Psychol 54: 25-53.

Rong R, Ahn JY, Huang H, Nagata E, Kalman D, Kapp JA et al (2003). PI3 kinase enhancer-Homer complex couples mGluRI to PI3 kinase, preventing neuronal apoptosis. Nat Neurosci 6: 1153-1161.

Sala C, Futai K, Yamamoto K, Worley PF, Hayashi Y, Sheng M (2003). Inhibition of dendritic spine morphogenesis and synaptic transmission by activity-inducible protein Homerla. J Neurosci 23: 6327-6337.

Shiraishi Y, Mizutani A, Mikoshiba K, Furuichi T (2003a). Coincidence in dendritic clustering and synaptic targeting of homer proteins and NMDA receptor complex proteins NR2B and PSD95 during development of cultured hippocampal neurons. Mol Cell Neurosci 22: 188-201.

Shiraishi Y, Mizutani A, Yuasa S, Mikoshiba K, Furuichi T (2003b). Glutamate-induced declustering of post-synaptic adaptor protein Cupidin (Homer 2/vesl-2) in cultured cerebellar granule cells. J Neurochem 87: 364-376.

Shiraishi Y, Mizutani A, Yuasa S, Mikoshiba K, Furuichi T (2004). Differential expression of Homer family proteins in the developing mouse brain. J Comp Neurol 473: 582-599.

Swanson C, Baker D, Carson D, Worley P, Kalivas PW (2001). Repeated cocaine administration attenuates group I metabotropic glutamate receptor-mediated glutamate release and behavioral activation: A potential role for Homer $1 \mathrm{~b} / \mathrm{c}$. J Neuroscience 21: 9043-9052.

Szumlinski KK, Dehoff MH, Kang SH, Frys KA, Lominac KD, Klugmann $\mathrm{M}$ et al (2004a). Homer proteins regulate sensitivity to cocaine. Neuron 43: 401-413.
Szumlinski KK, Frys KA, Kalivas PW (2004b). Dissociable roles for the dorsal and median raphe in the facilitatory effect of 5-HT1A receptor stimulation upon cocaine-induced locomotion and sensitization. Neuropsychopharmacology 29: 1675-1687.

Szumlinski KK, Lominac KD, Kleschen MJ, Oleson EB, Dehoff MH, Schwartz MK et al (2005a). Behavioral and neurochemical phenotyping of Homer1 mutant mice: possible relevance to schizophrenia. Genes Brain Behav 4: 273-288.

Szumlinski KK, Lominac KD, Oleson EB, Walker JK, Mason A, Dehoff $\mathrm{MH}$ et al (2005b). Homer2 is necessary for EtOH-induced neuroplasticity. J Neurosci 25: 7054-7061.

Tu JC, Xiao B, Yuan JP, Lanahan AA, Leoffert K, Li M et al (1998). Homer binds a novel proline-rich motif and links group 1 metabotropic glutamate receptors with IP3 receptors. Neuron 21: 717-726.

Tu JC, Xiao B, Naisbitt S, Yuan JP, Petralia RS, Brakeman P et al (1999). Coupling of mGluR/Homer and PSD-95 complexes by the Shank family of postsynaptic density proteins. Neuron 23: 583-592.

Xiao B, Tu JC, Petralia RS, Yuan JP, Doan A, Breder CD et al (1998). Homer regulates the association of group 1 metabotropic glutamate receptors with multivalent complexes of homerrelated, synaptic proteins. Neuron 21: 707-716.

Vagts AJ, He DY, Yaka R, Ron D (2003). Cellular adaptation to chronic ethanol results in altered compartmentalization and function of the scaffolding protein RACK1. Alcohol Clin Exp Res 27: 1599-1605.

Wolf ME (1998). The role of excitatory amino acids in behavioral sensitization to psychomotor stimulants. Prog Neurobiol 54: 679-720.

Yuan JP, Kiselyov K, Shin DM, Chen J, Shcheynikov N, Kang SH et al (2003). Homer binds TRPC family channels and is required for gating of TRPC1 by IP3 receptors. Cell 114: 777-789. 